that there are times when patients are admitted to in-patient beds under Section 136 for more than 48 hours, for example because the concerned Section 12(2)-approved doctor is reluctant to come out to complete the Section 136 assessment out of hours. There are few places where the Code of Practice is scrupulously followed and Section 12(2)-approved doctors are the first port of contact.

It makes you wonder that despite being a part of the legal system, Section 136 is very poorly managed as compared with the other sections of the Mental Health Act. There is no unitary form for Section 136 assessment documentation and no accountability for the assessments and detention of persons on Section 136. The time is right to make amends for this varied practice and for measures to be taken to get it right.

1 Tate L. Inexperienced trainees doing more Section 136 assessments (e-letter). Psychiatrist 2010; 26 July (http://pb.rcpsych.org/cgi/eletters/ 34/7/268\#10147)

Khurram Sadiq Locum Consultant Psychiatrist, Greater Manchester West Mental Health NHS Foundation Trust, email: khurramlodhi74@hotmail.com, Rupali Acharya, CT2 Psychiatry, Trafford.

doi: 10.1192/pb.34.11.499a

\section{Can making physical healthcare policies more readable improve healthcare standards?}

Gonzalez et al have pointed out an interesting omission in the form of poor physical healthcare monitoring in routine psychiatric practice and there is evidence from various local and national audits ${ }^{2,3}$ that it is not restricted to just the outpatient settings. The authors have also rightly picked up on key barriers to the implementation of physical healthcare monitoring in psychiatric settings, namely unclear responsibilities, competing demands on limited resources and liability issues. We believe that, for a start, this can be addressed by having readable, succinct and unambiguous physical healthcare policies.

Tosh et $a l^{4}$ examined the physical healthcare policy documents of the three mental healthcare trusts in the north sector of the East Midlands Strategic Healthcare Authority in detail. We found significant disparities between the policies in terms of size, readability, external references and reading cost. All the policies incorporated vague language in their directives and none could be read swiftly. It is only fair to make a reasonable observation here that if a policy cannot be accessed or is unfocused or vague, then it will be ignored.

Multiple layers of guidance and variation between deaneries, trusts and teams also complicate the situation. This leads to confusion and lack of confidence between team members as to which policy to follow. The result is a huge wastage of money from duplication and undermining of the ability of the policy to deliver its objectives.

A collaborative effort at the national level could produce a simple, clear and succinct policy for physical healthcare of people with serious mental illness. We believe that the Royal
College of Psychiatrists is in a unique position to take a lead on this very important aspect of patient health and well-being. There are already themes emerging from research that it is an area which is very important to the patients, carers and their families alike. ${ }^{5}$ A clear national policy statement from the College should dispel current confusion, policy fatigue and waste.

1 Gonzalez C, Ahammed N, Fisher R. Improving physical health monitoring for out-patients on antipsychotic medication. Psychiatrist 2010; 34: 91-4.

2 Abbasi Y. Improving physical health monitoring in psychiatry - change we need? Psychiatrist 2010; 34: 210-1.

3 Barnes TR, Paton C, Cavanagh MR, Hancock E, Taylor DM. A UK audit of screening for the metabolic side effects of antipsychotics in community patients. Schizophr Bull 2007; 33: 1397-403.

4 Tosh G, Clifton A, Adams CE. Physical health care policies in mental health trusts in the North East Midlands (UK). Mental Health Rev J 2010; 15: $15-20$.

5 McCrae J. Physical health concerns of the patient, the family and the carers. Eur Psychiatry 2010; 25 (suppl 2): 34-6.

Waqqas A. Khokhar Specialty Registrar, Radbourn Unit, Royal Derby Hospital, Derby, email: waqqaskhokhar@doctors.org.uk, Graeme Tosh Specialty Registrar, Nottinghamshire Healthcare NHS Trust, and Andrew Clifton Research Fellow, Institute of Mental Health, University of Nottingham.

doi: $10.1192 /$ pb.34.11.500

\section{A fishy business}

Has anyone else noticed that the epigram at the start of this paper ${ }^{1}$ is incorrectly attributed? It does not express a Taoist idea, and is not the kind of thing Lao Tsu would have written. Unfortunately, I have not been able to locate the original source. For example, it does not appear in the Oxford Dictionary of Quotations (where 20 reliable quotes from Lao Tsu are listed). At least one website also wrongly lists Lao Tsu as the author, and another refers to the quotation as a Chinese proverb, but a third calls it an English proverb. (I have been wondering if the original author might actually have been contemporary, an Oxfam official for instance.) I have checked again through Lao Tsu's Tao Te Ching, the only work of his that survives. 'Give a man a fish ... ' definitely does not appear. Indeed, the only (sole) reference to fish comes in Chapter 60: 'Governing a large country is like frying a small fish; you spoil it if you poke it around too much'. It occurs to me that a number of politicians, including particularly the Secretary of State for Health, might wisely take note of that point. What are the chances of them taking the bait?

1 Hill L, Roberts G, Igbrude W. Experience of support time and recovery workers in promoting WRAP. Psychiatrist 2010; 34: 279-84.

Larry Culliford author (retired psychiatrist), the Royal College of Psychiatrists, West Sussex, email: auud26@dsl.pipex.com

doi: 10.1192/pb.34.11.500a 